\title{
PERISSOMYRMEX SNYDERI (HYMENOPTERA: FORMICIDAE) IS NATIVE TO CENTRAL AMERICA AND EXHIBITS WORKER POLYMORPHISM
}

\author{
By J. T. Longino ${ }^{1}$ AND D. A. HartLey
}

\begin{abstract}
The rediscovery of Perissomyrmex snyderi, previously known from the two worker types, is reported. New collections were observed from two different cloud forest sites in the state of Chiapas, Mexico. Based on the collection localities and cloud forest habitats, the species is clearly native to Central America. A sample of 205 workers revealed diphasic allometry, with distinct minor and major worker castes, and the queen was observed for the first time.
\end{abstract}

\section{INTRODUCTION}

In 1947 M. R. Smith described a new genus and species of myrmicine ant, Perissomyrmex snyderi, based on two workers found in the tuberous root of a begonia plant intercepted at a United States quarantine station, in a shipment originating in Guatemala (Smith 1947). Smith considered the genus similar to Pristomyrmex, which is widespread in the Old World tropics. The species was still known from the types only when Bolton (1981) reviewed the African Pristomyrmex. Because of the affinity of Perissomyrmex and Pristomyrmex, and the fact that no additional Perissomyrmex had appeared in spite of extensive collecting in the neotropics, Bolton suggested that the species could be of Old World origin (Bolton 1981). Baroni Urbani and Andrade (1993) described a second species, $P$. monticola, based on two workers and a queen from $2800 \mathrm{~m}$ elevation in Bhutan. The discovery of this species in Bhutan strengthened the conjecture that Perissomyrmex was native to the Old World, with the New World occurrence of $P$. snyderi being due to "accidental introduction" (Baroni Urbani and Andrade 1993).

1 To whom correspondence should be addressed. The Evergreen State College, Olympia, WA 98505 USA.

Manuscript received 25 June 1994. 
We report here the rediscovery of $P$. snyderi in cloud forests of southern Mexico, which suggests a New World origin. We also report here for the first time that $P$. snyderi is polymorphic, and we describe the queen.

\section{New Collections}

In September, 1992, R. S. Anderson sampled forest floor leaf litter in a number of cloud forest sites in southern Mexico and in Guatemala. The Berlese samples were sent to us for extraction of the ants, and we discovered 205 workers and a dealate queen of $P$. snyderi. These were all from three adjacent samples, on the lower slopes of Volcán Tacana, North Union Juarez, $15^{\circ} 07^{\prime} \mathrm{N}, 92^{\circ} 06^{\prime} \mathrm{W}$, Chiapas, Mexico, between 1950 and $2000 \mathrm{~m}$ elevation. The workers were distinctly polymorphic.

P. S. Ward provided data on a second collection of $P$. snyderi. In December, 1991, he collected 9 workers of $P$. snyderi at a cloud forest site 9.1 road kilometers east of Rayón on Highway 195, $17^{\circ} 13^{\prime} \mathrm{N}, 92^{\circ} 58^{\prime} \mathrm{W}$, Chiapas, Mexico, at $1700 \mathrm{~m}$ elevation. $\mathrm{He}$ described the cloud forest as having more tropical than temperate elements, with Pinus and Liquidambar in the vicinity but not at this particular site. The workers were extracted from sifted leaf litter from the forest floor.

The queen and a worker series will be deposited at the Museum of Comparative Zoology, Harvard, and to make material of this rare genus generally accessible, workers from the Anderson collection will be dispersed widely to museums. The Ward specimens are in the Bohart Museum of the Department of Entomology, University of California, Davis; the Museum of Comparative Zoology, Harvard University; and the Natural History Museum, London.

\section{POLYMORPHISM}

Head width, head length, and Weber's length were measured for the 206 specimens in the Anderson collection. With the head in perfect full face view, head width was measured across the head at the upper margin of the eyes (not including eyes), and head length was measured from a line tangent to the rearmost extent of the vertex margin to the anteriormost portion of the clypeus (including clypeal teeth). Weber's length is the distance from the anterodorsal 
margin of the pronotum to the posterior margin of the metapleural lobes. Measurements were taken at $50 \times$ magnification, using a Nikon micrometer stage with an orthogonal pair of Boeckler rotary micrometers, wired to a dual-axis digital readout. Measurements were recorded to the nearest $0.001 \mathrm{~mm}$ but were generally repeatable to the nearest $0.005 \mathrm{~mm}$. We examined pair-wise $\log$-log plots of the three morphometric variables we measured, and examined the size-frequency distribution, following the methods and terminology of Wilson (1953). We also examined probability plots of variables using Systat ${ }^{\circledR}$ Version 5.2.

Head width and head length exhibited monophasic allometry. The log-log plot was tightly linear $\left(r^{2}=0.97\right)$ with a slope of 0.85 (head relatively wider in larger workers). In contrast, head width and Weber's length exhibited diphasic allometry (Fig. 1). The loglog plot may be interpreted as two line segments of differing slope

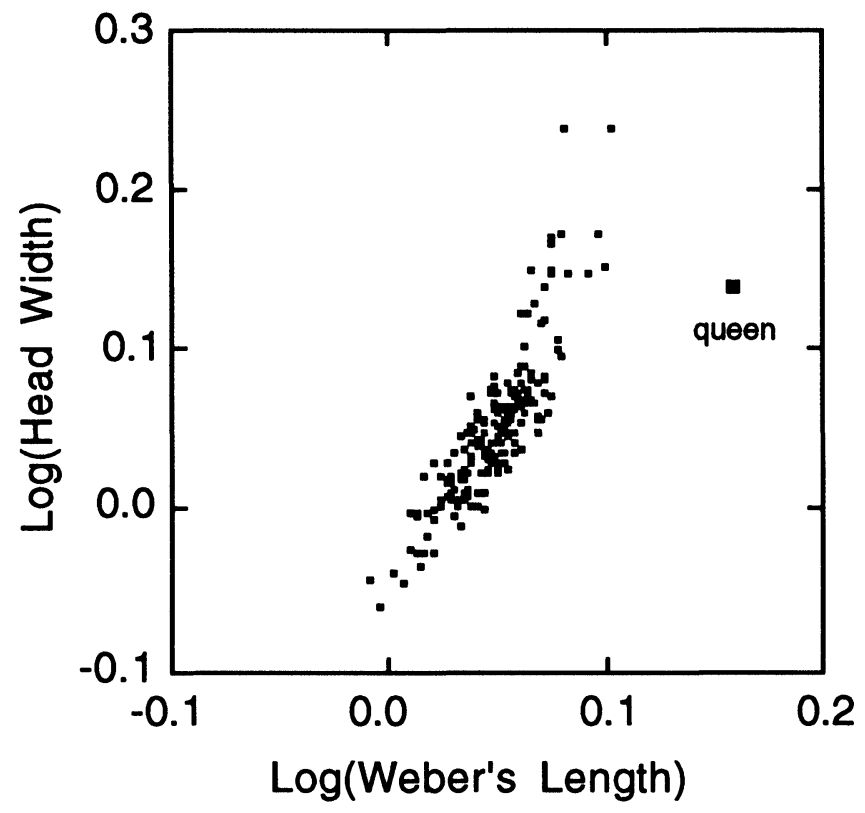

Fig. 1. Diphasic allometry in Perissomyrmex snyderi as revealed by a log-log plot of head width on Weber's length. $n=205$ workers and one queen. 


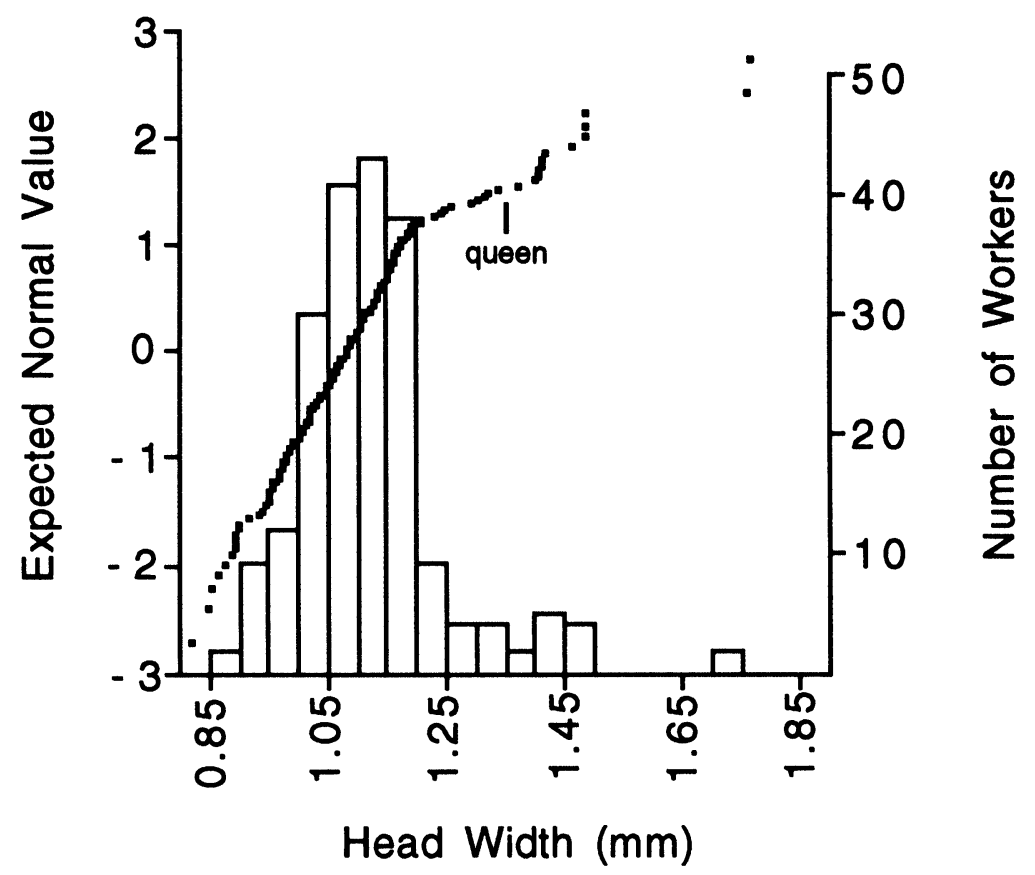

Fig. 2. Size frequency distribution of a field sample of Perissomyrmex snyderi. The dots are the observed head width values plotted against the expected values of a standard normal variable. Two line segments of differing slope are evidence of bimodality. Queen head width falls within the range of values for major workers.

(Wilson 1953) or a single curve (Wheeler 1991). The size-frequency distribution is bimodal (Fig. 2), suggesting distinct minor and major worker castes.

The Ward collection also exhibited polymorphism, with a series of eight minor workers (head widths $0.88-1.00 \mathrm{~mm}$ ) and a major worker (head width $1.35 \mathrm{~mm}$ ) (Ward, pers. comm.).

\section{MORPHOLOGY}

The two P. snyderi workers described by Smith had two pairs of teeth on the anterior clypeal border. In the sample described here, small workers usually have three pairs of teeth distributed across the anterior border, the median pair being the largest (Fig. 3). This 
$\mathbf{A}$

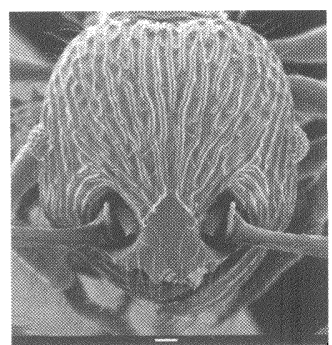

C

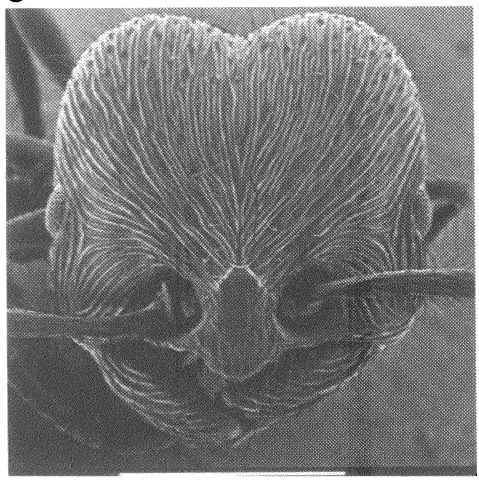

B

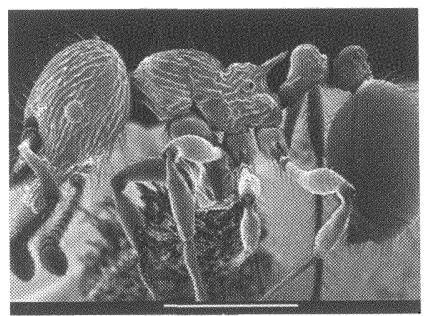

D

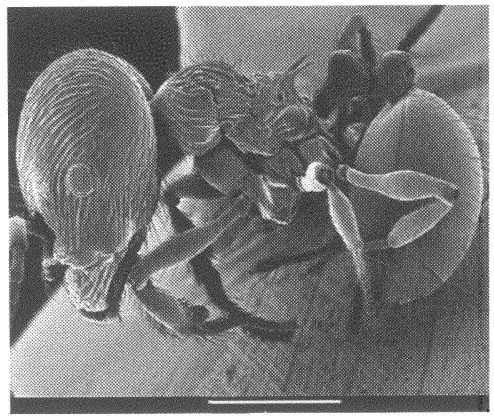

Fig. 3. Perissomyrmex workers. A. Minor worker, face. B. Minor worker, lateral. C. Major worker, face. D. Major worker, lateral. Scale bars are $0.1 \mathrm{~mm}$ (A) and $1.0 \mathrm{~mm}(B, C, D)$. Face views are to same scale, and lateral views are to same scale.

grades into a state in larger workers in which the outermost pair of teeth are lost, the next pair are reduced, and the median pair fuse into a single, large, blunt tooth (Fig. 3). The anterior border of the labrum bears a pronounced elevated ledge with sharply angular lateral margins (labrum features may have phylogenetic significance in the Myrmecinini; Bolton, pers. comm.).

The queen of $P$. snyderi has never been described. The shape and sculpture are identical to the illustration of a $P$. monticola queen in Baroni Urbani and Andrade (1993, fig. 3), differing only in the presence of a distinct anteroventral tooth on both petiole and postpetiole. Queen size is also very similar, the $P$. snyderi queen being slightly larger than the $P$. monticola queen. Measurements for the P. snyderi queen are head width 1.35 (1.20 in P. monticola), 
head length 1.27, Weber's length 1.44, scape length 1.01 . The anterior clypeal border has two pairs of distinct lateral teeth (like small workers) and a broad, blunt, projecting median tooth (like large workers with fused median teeth). Queen head shape is identical to the larger workers, falling among the workers on the log-log plot of head width vs. head length. Because the queen mesosoma is proportionally much larger, she is clearly differentiated from workers in the log-log plot of head width vs. Weber's length (Fig. 1).

\section{DISCUSSION}

The current distribution of Perissomyrmex is widely disjunct, with one species in Central America and one species in Asia. Possible explanations for this distribution are convergence, long-distance dispersal, or vicariance.

Convergence is unlikely. Both Pristomyrmex and Perissomyrmex are characterized by 1) clypeus projecting and dentate, 2) antennal sockets forming conspicuous circular wells with fully-exposed torulus, and 3) mandibles sublinear with masticatory margin downturned, perpendicular to clypeus. We are not prepared to discuss the phylogenetic significance of these particular traits, but numerous autapomorphies support the monophyly of a lineage containing both genera (Bolton, pers. comm.). The two Perissomyrmex species both have 9-segmented antennae, while Pristomyrmex has 11. In addition to this obvious meristic character, the two species of Perissomyrmex are almost eerily similar in details of size, shape, and sculpture. Perissomyrmex is undoubtedly a monophyletic lineage within the larger Pristomyrmex + Perissomyrmex clade.

Baroni Urbani and Andrade, and before them Bolton, proposed recent accidental introduction to explain the presence of $P$. snyderi in Central America. The new observations reported here make it highly likely that $P$. snyderi is native to Central America. It has now twice been collected from intact cloud forest, the two sites $240 \mathrm{~km}$ apart. In addition to Perissomyrmex, the litter samples have contained a typical assemblage of other native ants, including Stenamma, Adelomyrmex, Gnamptogenys, and dacetines. Obvious exotic species are lacking.

The third and most likely explanation is vicariance. Perhaps we are seeing the last remnant of an ancient and formerly widespread lineage, displaced by newer faunal elements, and now surviving in 
a specialized habitat (cloud forest). We predict that additional populations or species of this lineage may be found in isolated pockets, in cloud forest or other specialized habitats, elsewhere in the new and/or old world tropics. If the vicariance hypothesis is true, Perissomyrmex represents a case of extreme morphological stasis, since the two species are remarkably similar, differing only in minor sculptural features.

We observed polymorphism in P. snyderi, but the mechanisms behind it cannot be revealed with our data. Wheeler (1991) warns of the difficulties in interpreting size-frequency distributions from a standing crop of adult workers. A simultaneous size distribution of pupae will reveal polymorphism generated by social mechanisms (differential feeding of larvae) or intrinsic developmental mechanisms, whereas a size distribution of worker standing crop may be influenced by factors extrinsic to the colony: changes in resource availability over time or size-dependent mortality of workers (Wheeler 1991). The data reported here are from a standing crop of workers from at least two different colonies, and so we cannot state with confidence that the observed bimodal distribution is the result of an evolved caste system. However, the concordance of the log-log plots of morphometric data and the break in the curve of the probability plot for the size-frequency data strengthen the conjecture.

\section{ACKNOWLEDGMENTS}

We thank Robert Anderson for providing the litter samples, and Barry Bolton, Phil Ward, and Ed Wilson for generous assistance. This work was supported by the National Science Foundation and by the Office of Forestry, Environment and Natural Resources, Bureau of Science and Technology, of the U.S. Agency for International Development under NSF Grant No. BSR-9025024, and by Sponsored Research awards from The Evergreen State College.

\section{Literature Cited}

Baroni Urbani, C., and M. L. de Andrade. 1993. Perissomyrmex monticola n. sp., from Bhutan: the first natural record for a presumed Neotropical genus with a discussion on its taxonomic status. Tropical Zoology 6:89-95.

Bolton, B. 1981. A revision of six minor genera of Myrmicinae (Hymenoptera: Formicidae) in the Ethiopian zoogeographical region. Bull. Br. Mus. Nat. Hist. (Ent.) 43:245-307. 
Smith, M. R. 1947. A new genus and species of ant from Guatemala (Hymenoptera, Formicidae). J. New York Ent. Soc. 55:281-284.

Wheeler, D. E. 1991. The developmental basis of worker caste polymorphism in ants. Amer. Natur. 138:1218-1238.

Wilson, E. O. 1953. The origin and evolution of polymorphism in ants. Quart. Rev. Biol. 28:136-156. 

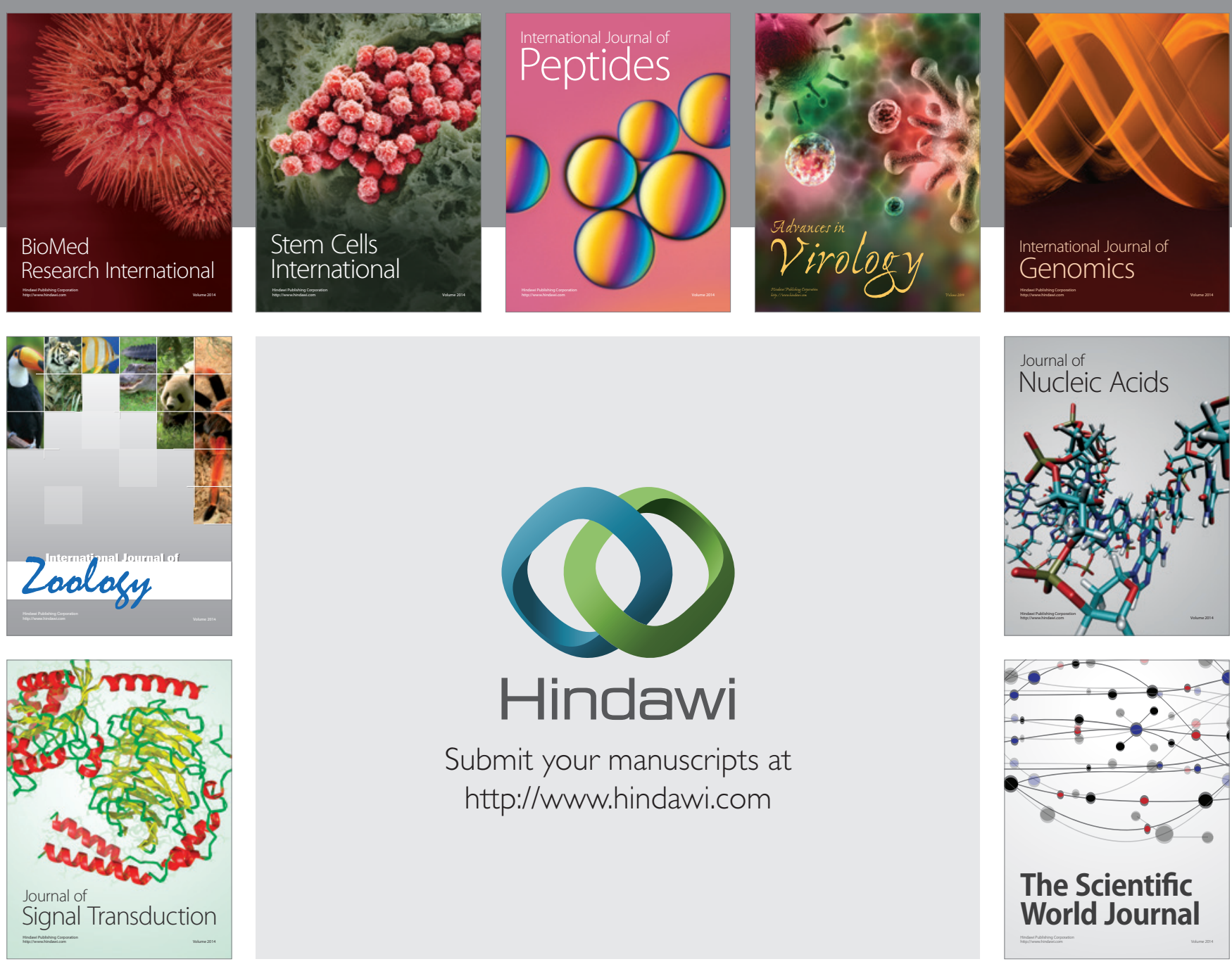

Submit your manuscripts at

http://www.hindawi.com
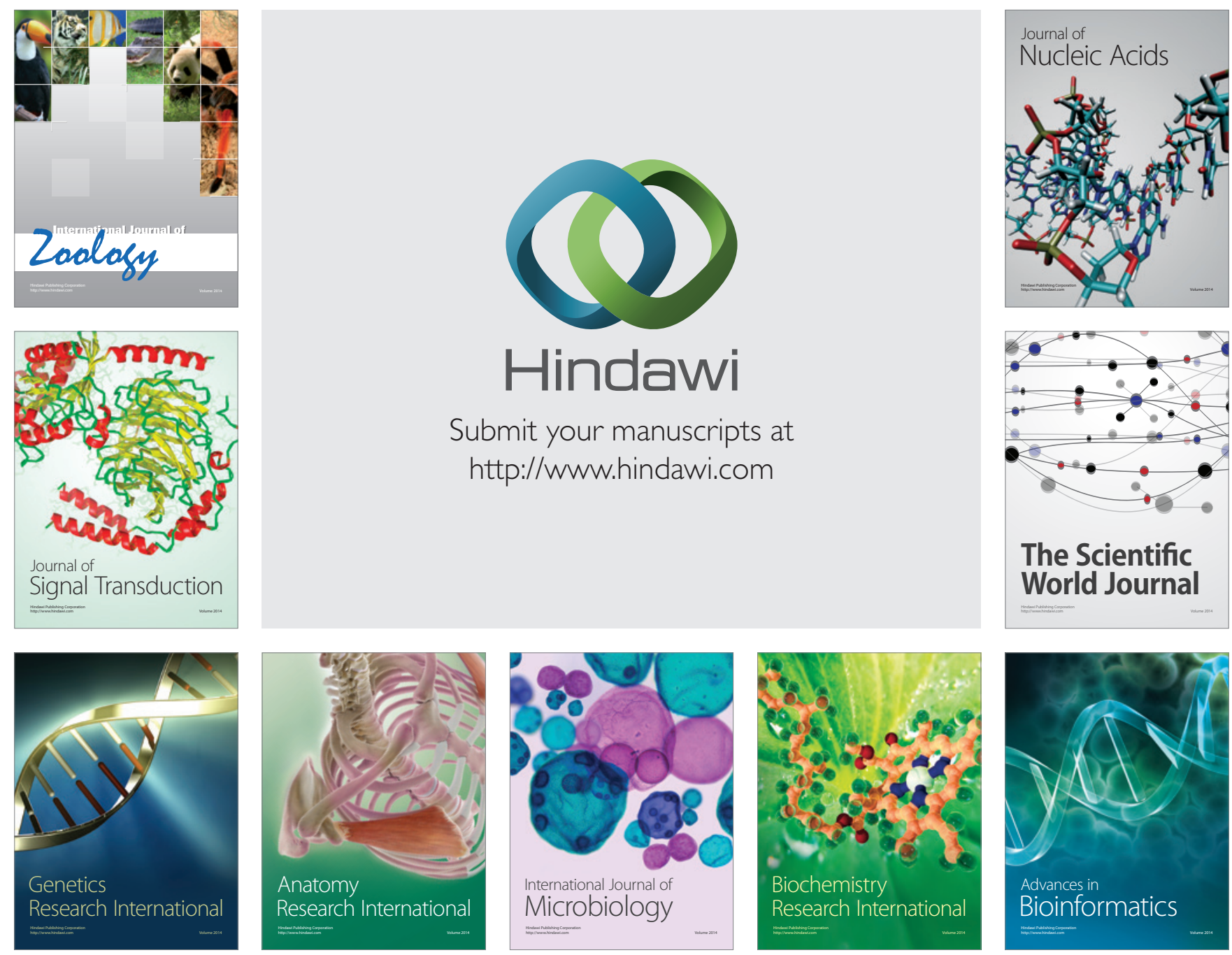

The Scientific World Journal
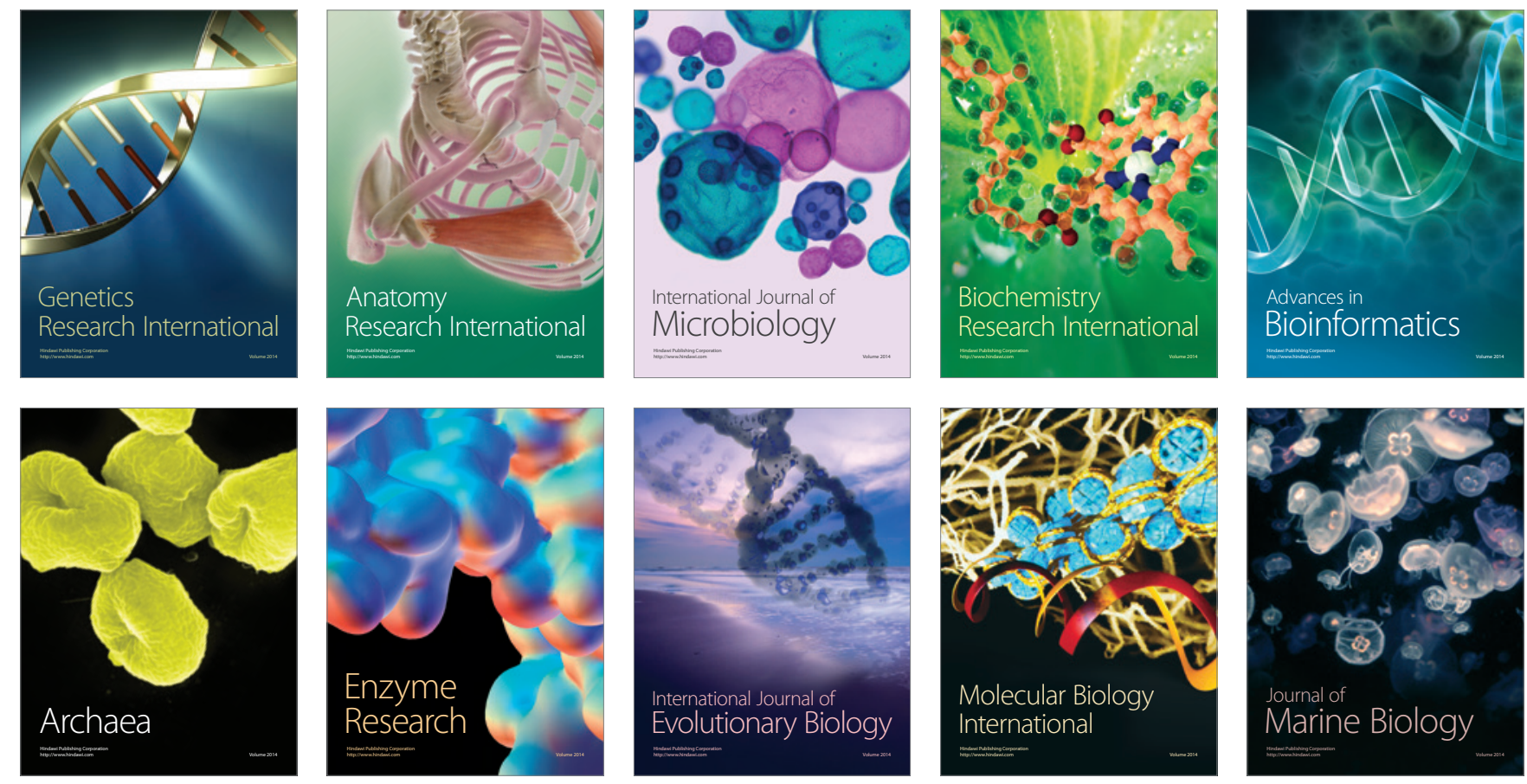